\title{
Responsabilidad Social Corporativa en el Patrocinio Deportivo
}

\author{
Luis Felipe Solano SANTOS \\ Universidad Complutense de Madrid \\ lfsolano@yahoo.es
}

\begin{abstract}
Resumen
El presente artículo pretende determinar el grado de responsabilidad social que corresponde a las actividades de patrocinio deportivo o esponsorización, es decir, el grado de asunción de responsabilidad que con su conducta asumen las organizaciones que realizan actividades de esta índole, de innegable naturaleza publicitaria y elevada rentabilidad económica, por otra parte. Para ello, se parte del concepto de responsabilidad social corporativa, que después de fundamentarse desde una reflexión teorética lógico-formal, se vincula y aplica al campo del patrocinio deportivo como instrumento de comunicación.
\end{abstract}

Palabras clave: patrocinio deportivo, responsabilidad social, comunicación, publicidad

\section{Corporate Social Responsibility in the Sports Sponsorship}

\begin{abstract}
This article aims to determine the degree of Social Responsibility that concerns to the activities of sports sponsorship, that is, the degree of responsibility assumption related to the organizations by conducting such activities. A kind of assumptions that have an undeniably advertising nature and, on the other side, a high economical profitability. This is done by starting on the concept of corporate social responsibility, founded on a formal logical theoretical reflection, and then bounded and applied to the field of sports sponsorship as a communication tool.
\end{abstract}

Key words: sports sponsorship, social responsibility, communication, advertising

\section{Referencia normalizada:}

Solano Santos, L. F. (2013) Responsabilidad Social Corporativa en el Patrocinio Deportivo. Historia y Comunicación Social. Vol. 18 No Especial Octubre. Págs. 255-265

Sumario: 1. Introducción; 2. Instrumentos de Responsabilidad Social Corporativa; 3. Diferencias entre patrocinio deportivo y otras formas de patrocinio; 4 . Conclusiones; 5 . Referencias bibliográficas.

\section{Introducción}

Sin lugar a dudas, el patrocinio deportivo o esponsorización no sólo supone en la actualidad una de las principales fuentes de ingresos para el deporte, sino también constituye un magnífico escenario para las empresas patrocinadoras de todo el mundo que rentabilizan con creces las inversiones realizadas en este campo. 
Se trata, por tanto, de una de las formas de patrocinio más importantes y practicadas por las entidades privadas. Prueba de ello es que no hay un solo acontecimiento deportivo que no lleve de la mano un patrocinador que aproveche esa gran expectación que rodea o levanta cualquier evento de estas características en casi todo el mundo y, por supuesto, en España. Nuestro país ha acogido esta fórmula de forma extraordinaria por motivos obvios: se practican muchos deportes y con gran frecuencia; existe una gran afición al deporte; y por último, se ofrece una gran cobertura mediática.

Por estas razones y otras que abordaremos a continuación, los empresarios han visto un filón que no dejan de aprovechar un instante. Incluso las grandes figuras del deporte se han convertido en hombres anuncio. Un ejemplo de ello son Rafael Nadal, Fernando Alonso, Pau Gasol... quienes portan casi siempre las marcas de las empresas patrocinadoras. Y es que las principales compañías vinculadas o no al deporte a través de la función que desempeñan hacen lo imposible por aprovechar la popularidad, simpatía y, sobre todo, liderazgo de estas figuras conocidas mundialmente.

Pero la cosa no queda ahí, puesto que los estadios, polideportivos, es decir, los lugares o espacios donde se celebran este tipo de eventos se han convertido en unos magníficos escenarios. Tal es así que hay quien incluso critica este aspecto aduciendo que en lo que de verdad se han transformado es en supermercados de la publicidad, cuyo único objetivo es persuadir al público que acude a disfrutar de un acontecimiento deportivo y finalmente es bombardeado sin cesar por las marcas y empresas patrocinadoras que se publicitan a través de todo tipo de formas y soportes.

El deporte es un gran gancho para el empresariado que ha encontrado ese filón que no duda en utilizar sin descuidar detalle alguno. Es cierto que es altamente comercial y rentable, pero también se atisba un resquicio en lo que a Responsabilidad Social se refiere, puesto que de no ser por las empresas que invierten sumas de dinero en muchas ocasiones desorbitadas no sería posible la celebración de muchos eventos deportivos, sobre todo, los más relevantes.

Pero ¿Qué es la Responsabilidad Social Corporativa? Trataremos de responder a esta pregunta, como a otras, con objeto de aclarar su concepción, fundamentación y aplicación al ámbito del deporte en su relación con la comunicación. Es decir, estableceremos el grado de responsabilidad social que corresponde a las actividades de patrocinio deportivo o esponsorización, esto es, el grado de asunción de responsabilidad que con su conducta asumen las organizaciones que realizan actividades de esta índole, que coincide con el fundamento de las propias Relaciones Públicas, o sea, que el grado de aceptación social de una corporación está en función del comportamiento de esta naturaleza, que no es otro, sino el correspondiente al comportamiento esperado. 


\section{Instrumentos de responsabilidad social corporativa}

Actualmente no puede obviarse que la Responsabilidad Social se ha convertido en uno de los principales activos y valores de cualquier corporación, es decir, aquella entidad que por su volumen y capacidad está en condiciones de liderar el progreso social en todos los órdenes. Indudablemente tras el estallido de la aún vigente crisis económica a nivel mundial, muchos somos los que hemos denunciado que el incumplimiento de la Responsabilidad Social Corporativa es la principal causa de la misma. Pero ¿qué es en realidad la Responsabilidad Social Corporativa?

Dividir en partes la expresión para luego examinar cada una de ellas nos proporcionará un conocimiento pleno del todo, en este caso, del concepto en cuestión.

Responsabilidad es conocer y aceptar las consecuencias de un acto libre e inteligente, así como la relación de causalidad que une al autor con el acto que realiza, vinculando en aquél las relaciones nacidas de los efectos de éste. Que responsabilidad equivale a obligación o conjunto de obligaciones derivadas de la libre asunción de un estado o condición y que hablar de obligación nos remite directamente al problema de la costumbre, norma creada e impuesta por el uso social, según Federico de Castro.

Entendemos por Responsabilidad Social el conjunto de obligaciones inherentes a la libre asunción de un estado o condición, aun no reconocidas por el ordenamiento jurídico positivo o reconocidas sólo parcialmente, pero cuya fuerza vinculante y su previa tipificación proceden de la íntima convicción social de que su incumplimiento constituye una infracción de la norma de cultura (Solano Fleta: 1995).

Si la Responsabilidad Social es conjunto de obligaciones inherentes a la libre asunción de un estado o condición debemos concretar de dónde derivan dichas obligaciones.

Desde la perspectiva jurídica conceptual, obligatio est iuris vinculum, es decir, la obligación es un vínculo de derecho por virtud del cual estamos obligados a dar, hacer o no hacer alguna cosa a alguien. Pues bien, las obligaciones a las que nos referimos al hablar de Responsabilidad Social son aquellas, en primer lugar, que derivan o emanan de la propia actividad o función que desarrolla o desempeña la organización; y en segundo lugar, una serie de obligaciones derivadas en función del impacto que la organización tenga en la sociedad a todos los niveles, es decir, político, económico, medioambiental y social.

La primera dimensión hace referencia a un comportamiento al que toda organización está obligada a llevar a cabo, es decir, toda organización debe ser socialmente responsable al desempeñar su propia función, o sea, la actividad para la que ha nacido; mientras que la segunda dimensión se refiere a una serie de obligaciones nacidas o derivadas del tremendo y extraordinario impacto que las corporaciones tienen sobre el sistema político y económico, la sociedad y el medio ambiente.

Entre otras muchas, las acciones de patrocinio y mecenazgo figuran en esa segunda dimensión, puesto que se trata de una serie de requerimientos sociales exigibles a las 
organizaciones que por su volumen y envergadura están en condiciones de liderar el progreso social.

Ahora bien, el mundo empresarial, el "mundo de los negocios", en el decir angloamericano, sostenía y nos atrevemos a afirmar que sostiene en la actualidad, la responsabilidad social de la empresa, es decir, una responsabilidad que trasciende los angostos límites de la contenida en los textos legales que regulan la actividad industrial y mercantil y demás normas complementarias y que abarcan multitud de aspectos. Los economistas, al menos un sector suficientemente significativo de ellos, limitan esa responsabilidad al campo económico, afirmando que la responsabilidad de la empresa consiste, ni más ni menos, en la obtención del máximo beneficio, sin que se le pueda atribuir ninguna otra obligación, excepción hecha, claro está, de las de carácter fiscal, laboral, etc., a las que habría que añadir las que la presión social de la hora presente va cargando sobre sus "espaldas" (respeto del medio ambiente, lucha contra la contaminación, etc.).

No obstante y aunque aparentemente ambas posturas divergen radicalmente, la realidad no es así, ya que sus fronteras distan mucho de ofrecer perfiles nítidos y claramente diferenciados, supuesto que sus fundamentos se hallan en ámbitos dispares, obedientes las más de las veces a concepciones políticas, sociales y religiosas inspiradoras de unas filosofías vitales de carácter emocional o intuitivo y desde luego, de muy difícil racionalización, siquiera se nos presenten o pretendan presentar rodeadas de un halo de "cientificismo".

Ahora bien, la inmensa mayoría de las instituciones sociales, es decir, los entes colectivos formales, entre los que figuran el estado, la empresa económica, los partidos políticos y en última instancia, las instituciones más importantes de nuestro sistema sociopolítico, o sea, aquellos factores sobre los que reposa la civilización, surgen o parecen surgir como categorías históricas, es decir, elementos o ingredientes susceptibles de asegurar, en el momento exacto, el desenvolvimiento de la sociedad humana y su progresión "ad infinitum".

La carencia de una fundamentación rigurosa ha determinado que haya habido que esperar siglos para que el mundo empresarial adquiera conciencia de su responsabilidad, una conciencia social de lo que inicialmente se identifica como filantropía y, más tarde, como responsabilidad social.

La responsabilidad social adolece de una gravísima carencia inicial y es el hecho de su voluntariedad, o dicho con otras palabras, el dejarlo al arbitrio de sus propios actores y únicamente castigado su incumplimiento con una difusa sanción social.

Los economistas limitan esa responsabilidad al campo económico, afirmando que la responsabilidad de la empresa consiste, ni más ni menos, en la obtención del máximo beneficio, sin que se le pueda atribuir ninguna otra obligación, excepción hecha, claro está, de las de carácter fiscal, laboral, etc., a las que habría que añadir las que la presión social de la hora presente va cargando sobre sus "espaldas" (respeto del medio ambiente, lucha contra la contaminación, etc.). 
Se trata de un tema polémico. En gran medida, resulta sorprendente que fuera el mundo del Derecho el primero que dio el gran paso y en una institución que, desde Roma, se había considerado perfectamente cristalizada: el derecho de propiedad. Para el romano, en efecto, la propiedad era el "ius utendi, fruendi et abutendi", es decir, el derecho de usar, disfrutar e incluso abusar de las cosas. En palabras infinitamente más elegantes y sin perder un ápice de rigor, nuestros grandes romanistas lo definían diciendo que era "el señorío jurídico sobre las cosas" (Iglesias Santos: 1957). Sin embargo, el derecho de propiedad estuvo sujeto a diversas limitaciones que, con el paso de los tiempos, fueron perfilándolo hasta convertirlo en una sombra de lo que antaño fue. La propiedad se concibe actualmente como un derecho social, por encima del cual se hallan los intereses de la sociedad, que priman siempre y en todo caso sobre él. Sea como fuere, es lo cierto que la concepción del derecho de propiedad influyó sobremanera en la idea de la responsabilidad social que estudiamos. La empresa está al servicio de la sociedad porque maneja recursos humanos y materiales naturalmente escasos, recursos que detrae del cuerpo social y que al dedicarlos a la producción de bienes o servicios determinados significa también que impide su aplicación a otros menesteres. Una analogía casi caricaturesca nos lo demuestra.

La responsabilidad social corporativa no debe estimarse jamás como una opción voluntaria por parte de las corporaciones, sino como una obligación ineludible que, en el futuro, será jurídicamente exigible incluso ante los órganos jurisdiccionales.

Cuando se habla de responsabilidad social corporativa, es como si se tratara de una manifestación actitudinal defensiva ante circunstancias intolerables: la defensa del entorno, el salario justo, la defensa de los intereses del usuario o consumidor, etc. Ello es correcto y no hay nada que añadir; sin embargo, nosotros entendemos que hay que dar un paso adelante y dejar de configurar la responsabilidad social desde puntos de vista reactivos, sino activos, lo cual se corresponde con la figura, todavía escasamente desarrollada, del ciudadano corporativo.

En efecto, la empresa, la corporación, si se quiere, ha experimentado un grado de crecimiento tal que ha superado todas las previsiones; ya no es concebible la empresa que limita sus actividades a un mercado local, regional o incluso, nacional; sus acciones han desbordado fronteras y no sólo en el ámbito económico, sino también en el político; su poder económico ha desestabilizado gobiernos y ha impuesto, en ocasiones, gobiernos dictatoriales, usurpando la voluntad y la capacidad de decisión de los pueblos. No hace falta recordar el caso de Chile, en el que la ITT "derribó" al legítimo gobierno de Allende, apoyando al general "golpista" Augusto Pinochet e imponiendo una dictadura presumiblemente acorde con sus intereses.

Al hablar de responsabilidad social corporativa, muchas personas pueden caer en la fácil tentación de considerar este tipo de responsabilidad como una especie de capricho o moda pasajera, hija de los tiempos que vivimos. 


\section{Diferencias entre patrocinio deportivo y otras formas de patrocinio}

Respecto del resto de modalidades del patrocinio, la esponsorización se diferencia fundamentalmente por tres características específicas muy concretas que son las siguientes:

1. Visibilidad

2. Audiencia

3. Presencia mediática

Vamos a ver por qué razones la visibilidad, audiencia y presencia mediática difieren de forma notable en el patrocinio deportivo respecto del resto de formas.

Visibilidad: el patrocinio deportivo es bastante más visible que cualquier otro tipo de patrocinio, ya que todo a su alrededor está enfocado a la publicidad. Todo objeto, infraestructura o cualquier otra cosa similar se convierte, transforma o utiliza como soporte publicitario. El logotipo o la imagen de marca de una empresa es mucho más visible porque se cuenta con más medios y más audiencia.

Audiencia: el patrocinio deportivo se dirige a la gran masa, es decir, a un público que no está nada segmentado y que es muy diverso y numeroso. Eso sí, se trata de un público enormemente interesado y extremadamente motivado que no pierde detalle alguno de la retransmisión o evento deportivo. Cuestión interesantísima para las empresas patrocinadoras, ya que se aseguran el ser más que visibles.

Presencia mediática: el patrocinio deportivo tiene asegurada la presencia de los medios de comunicación debido a las razones anteriormente referidas. El deporte es muy demandado por el público lo que conlleva una gran cobertura mediática. Cuestión muy interesante para las empresas patrocinadoras. Indudablemente se trata como muchos aseguramos de una apuesta segura y extraordinariamente rentable.

Como corolario subrayar que es innegable que el patrocinio deportivo o esponsorización transmite una serie de valores lo que acentúa aún más ese resquicio que atisbamos en todo acontecimiento o evento deportivo en lo a que responsabilidad social se refiere. Indudablemente el deporte transmite valores tan importantes como la superación, competitividad, esfuerzo, compañerismo, sacrificio, constancia, liderazgo, éxito, aspiración, etc..

Por otra parte, el patrocinio deportivo o esponsorización requiere una planificación, es decir, una estrategia. Las organizaciones deben tener en cuenta una serie de requisitos, reglas o pautas a la hora de embarcarse o involucrarse en una acción de estas características:

1. A ser posible patrocinar un acontecimiento deportivo o deporte relacionado con nuestra actividad, producto o marca. 
2. Lograr asociar nuestra imagen corporativa o de marca, producto o servicio a algún club de élite o figura del deporte, ya sea mítica o actual.

3. Asegurarse la presencia o cobertura de los medios de comunicación (está en función de la magnitud del acontecimiento o evento deportivo).

4. Adecuar nuestra imagen y logotipos a los distintos soportes publicitarios con objeto de lograr la visibilidad adecuada que nos proporcione la máxima rentabilidad.

5. Potenciar los comunicados de prensa, notas de prensa, dossier de prensa relacionadas con el acontecimiento deportivo dado con objeto de lograr la mayor resonancia mediática posible.

6. Poner en marcha todo tipo de promociones publicitarias y comerciales antes, durante y después del evento deportivo con objeto de reforzar la imagen corporativa, de marca, producto o servicio.

7. Realización de una campaña publicitaria y de relaciones públicas de apoyo a la esponsorización en los medios de comunicación que emitan noticias, entrevistas o reportajes fruto de las notas de prensa remitidas relacionadas con el patrocinio (Andrés: 1993).

\section{Conclusiones}

A la hora de establecer un precedente del reconocimiento de responsabilidad social, muy pocos expertos somos los que dudamos en señalar que éste se halla en el patrocinio y mecenazgo. Sin duda, es la primera manifestación de ello; que, íntimamente unido a la filantropía, ambas instituciones son, aunque tímidamente expresadas, realizaciones que traducen una clara conciencia social de que el mundo de los negocios está en deuda permanente con la sociedad que lo acoge y que, en definitiva, es la que hace posible su existencia y desarrollo.

Ahora bien, patrocinio y mecenazgo encapsulan un riesgo muy grave, riesgo que todavía arrastramos y mucho nos tememos continuaremos arrastrando durante mucho tiempo; resulta curioso, por otra parte, que acciones empresariales que forman parte de lo que se ha calificado con entera justicia de filantropía empresarial, es decir, expresión o manifestación de un talante generoso hacia la sociedad, sean al propio tiempo uno de los mayores obstáculos con que ha tropezado hasta el presente la responsabilidad social corporativa. Pero, esta afirmación exige inmediata aclaración, a fin de que no se interprete torticeramente.

El patrocinio y mecenazgo son, como hemos visto más arriba, acciones filantrópicas y en consecuencia, totalmente voluntarias, por virtud de las cuales la empresa devuelve a la sociedad parte -pequeña- de sus beneficios y se trata, repetimos, de actividades absolutamente voluntarias; el hecho de que en algunos países sea posible 
desgravar fiscalmente su coste, ni añade ni quita valor a las mismas -al menos, presumamos la buena fe-, entre otras razones, porque primero fue el hecho y después la consecuencia y nos referimos al dato fiscal.

Ahora bien, prescindiendo de que, en numerosas ocasiones, se trata de verdaderas inversiones -inversiones en imagen social, en desgravaciones fiscales, en posicionamiento político, etc.-, e incluso, como afirmamos antes, presumiendo la buena fe en sus autores, el patrocinio y mecenazgo ha creado la falsa conciencia de hacerlos depender del libre arbitrio de sus autores, lo que ha retrasado hasta la fecha su consideración de actividades exigibles por parte de la sociedad. Pero, aun hay más; en el patrocinio y mecenazgo, la empresa que los ejerce elige caprichosamente todas y cada una de las circunstancias que los rodean, que o bien puede ser la reconstrucción de un monumento, la erección de un orfanato, la creación de becas o de premios a la investigación y un larguísimo etcétera, inacabable como inacabable es el universo de las acciones humanas.

Conviene tener presente que, salvo pequeñas excepciones, las actividades de patrocinio y mecenazgo se corresponden con las inquietudes personales de la cúpula directiva de la organización o dicho de otro modo, con las personas que tienen la capacidad de decisión, y hemos dicho "inquietudes", por no decir el capricho o la afición. Muestra de lo que acabamos de decir la encontramos, sin ir más lejos, en el patrocinio de las actividades náuticas (ahí está, por ejemplo, el yate "Fortuna" y desearíamos que alguien nos dijera qué tiene que ver el "yachting" con el tabaco, y no es válido decir que los marinos, incluso amateurs, fuman, entre otras cosas, porque no es verdad y en segundo lugar, porque si lo hicieran utilizarían la pipa y además, porque en el supuesto de que fumaran cigarrillos, nunca serían de la marca "Fortuna", que es muy mala).

¿Y qué es el Patrocinio y Mecenazgo? Pues algo tan sencillo como adecuar sus contenidos a las necesidades y requerimientos sociales y una vez hecho esto, conectarlo con la norma de cultura de la sociedad; se trata, en definitiva, de conocer lo que quiere la comunidad y después, conectarlo con su impacto psicológico y con los fines de la organización.

Desde esta perspectiva observamos también el Patrocinio deportivo o Esponsorización, pues aunque posea una gran carga comercial y sea, como es, tremendamente rentable o así se considere, los eventos deportivos no dejan de ser requerimientos sociales que deben satisfacerse plenamente como si de otros se trataran. Es decir, aunque las empresas patrocinadoras rentabilizan, en ocasiones extraordinariamente, este tipo de estrategias que contienen un innegable componente publicitario, no es menos cierto que de no ser por dicha participación acontecimientos tan importantes y relevantes para nuestra sociedad como son los Juegos Olímpicos, el Mundial de Fútbol, el torneo de Wimbledon, etc., no serían posibles, lo que implica que reconozcamos ese grado, aunque sea mínimo, de responsabilidad social que con su conducta expresan las corporaciones que invierten, financian o costean actividades deportivas. 
De todo lo dicho se desprende como corolario que el Patrocinio y el Mecenazgo debe realizarse tras estudios muy detallados y rigurosos acerca de las actitudes de los "públicos" específicos de la empresa y obviamente, en conexión psicológica con el producto, que no deben obedecer al capricho, gustos o aficiones de los directivos y que debe tenerse en cuenta que se trata de instrumentos de comunicación susceptibles de afectar a la imagen de la organización.

En cualquier caso y a fin de aclarar las ideas, no viene mal recordar al lector lo que es el patrocinio, dejando a un lado el mecenazgo, pues no en vano abordamos el patrocinio deportivo:

Patrocinio es la ayuda económica, o de otro tipo, generalmente con fines publicitarios, que se da a una persona para que pueda realizar una actividad; así como una técnica de comunicación estructurada, mediante la cual una empresa -patrocinadorofrece unos recursos en forma monetaria o en especie a una organización, evento o causa - patrocinado- con la finalidad de obtener un beneficio directo al asocial su imagen, corporativa o de marca, sus productos o servicios, a la actividad o entidad patrocinada.

Entonces, patrocinio deportivo será toda ayuda económica o de otro tipo, generalmente con fines publicitarios, que se da a una persona para que pueda realizar una actividad relacionada con el deporte; así como una técnica de comunicación estructurada, mediante la cual una empresa -patrocinador- ofrece unos recursos en forma monetaria o en especie a una organización, evento o causa deportiva -patrocinadocon la finalidad de obtener un beneficio directo al asocial su imagen, corporativa o de marca, sus productos o servicios, a la actividad o entidad patrocinada

Como puede observarse, en esa ley no escrita pero que la naturaleza y la historia parecen haber grabado en el espíritu de todas las cosas, de un modo u otro, antes o después, todo recupera su peculiar destino, al fatum latino, y tanto patrocinio como publicidad, que son técnicas de comunicación y en consecuencia competen a las Relaciones Públicas (su estudio, su ejercicio y su realización) y su contenido se inserta en el ámbito de la responsabilidad social corporativa.

Si bien estamos de acuerdo con gran parte de las ideas volcadas por los autores de la materia, disentimos de sus conclusiones, al promover una concepción final del fenómeno en cuestión que lo ancla, prácticamente de modo exclusivo en el angosto ámbito de un pragmatismo trasnochado y lo calificamos de trasnochado, pese a que reconocemos que todavía y nos tememos que por mucho tiempo, se halla plenamente vigente.

De todo lo dicho se desprende que la redefinición del concepto de patrocinio, así como de patrocinio deportivo o esponsorización deben pasar inexorablemente por la redefinición, a su vez, del concepto de responsabilidad social corporativa, que como hemos repetido hasta la saciedad, nunca y repetimos una vez más, nunca debe estimarse como un acto de liberalidad empresarial, sino como un conjunto de obligaciones; y desde luego, tampoco debe considerarse como una técnica, más o menos difícil, 
más o menos efectiva, de obtener una ventaja competitiva sostenible a largo plazo, o como un instrumento de autodefensa frente a circunstancias sociales adversas.

Esperemos que cuando las aguas vuelvan a su cauce o descubran su curso natural, que es fatal e inexorable, la empresa asuma la responsabilidad social que le corresponde, comenzando por encargar su ejecución a los profesionales a quienes compete y no a advenedizos tecnócratas encapsulados en un economicismo ciego y petulante.

Habrá advertido, sin duda, el lector, que cuando hablamos de los profesionales competentes, hay que entender que nos referimos a los publirrelacionistas, que son los únicos preparados específicamente para el desempeño de semejantes funciones y desde el punto de vista académico institucional, a los licenciados en Ciencias de la Información y concretamente, en Publicidad y Relaciones Públicas que para algo están las Facultades de Ciencias de la Información y no incurramos en un defecto típicamente español y que consiste en que nuestros jóvenes se preparan para ser ingenieros, licenciados, etc., en esto o lo otro y luego se dedican a algo que no tiene la menor relación con sus conocimientos.

Creemos que lo afirmado más arriba no tiene nada que ver con el corporativismo, sino con el sentido común más elemental, el mismo que le hizo decir a nuestro inmortal Goya "zapatero a tus zapatos".

Hora es ya de que algún ejemplo aclare lo que hemos dicho en los párrafos precedentes, y lo vamos a hacer contra fácticamente, a fin de que se vea con mayor claridad. Una empresa dedicada a la producción de bebidas espirituosas no puede lógicamente patrocinar las ligas antialcohólicas y si lo hace, debe provocar inconscientemente el efecto contrario, lo que iría en contra de la norma de cultura.

Como vivimos en una época absolutamente "nominalista" por la influencia mercantilista del "Gigante del Norte", existe la creencia de que basta cambiar el nombre de las cosas para hacerlas diferentes; ahí tenemos, sin ir más lejos, al llamado "Marketing con causa", cuya razón de ser alcanza cotas de una inmoralidad difícilmente superable: se trata, ni más ni menos, de justificar una mala acción con otra buena. No vamos a citar ejemplo alguno, ya que estimamos que están en la mente de todos nuestros lectores. Claro está que, desde un punto de vista histórico y psicológico, la razón es fácil de adivinar: es una manifestación evidente de la clásica hipocresía del puritanismo protestante; no en balde nació en los Estados Unidos, en la América blanca, anglosajona y protestante.

No sabemos si debido a nuestro carácter o a nuestra educación, rechazamos visceralmente estas manifestaciones pseudoaltruistas, que encapsulan, como el veneno las serpientes, un pragmatismo feroz, más propio de una cultura púnica que de una civilización grecorromana. Y desde luego, desde una perspectiva publirrelacionista, a la que corresponde fijar la naturaleza y alcance de la responsabilidad social corporativa, el rechazo es asimismo total, porque no se trata de altruismo, sino de satisfacción de una obligación social y ello no es jamás un acto voluntario. 


\section{Referencias bibliográficas}

ANDRES, Amado J. de (1993) Mecenazgo y Patrocinio. Las claves del Marketing del siglo XXI. Madrid, Editorial Editmex

IGLESIAS SANTOS, Juan (1957) Derecho romano y esencia del Derecho. Barcelona, Ariel.

PARES I MAICAS, Manuel (1991) La Nueva Filantropía y la comunicación social. Barcelona, PPU

RABANAL, Marc (2004) El Patrocinio y Mecenazgo empresarial, en el marco de la Responsabilidad Social Corporativa. Barcelona, Ed. AEDME

SOLANO FLETA, Luis (1995): Fundamentos de las Relaciones Públicas. Madrid, Síntesis.

SOLANO SANTOS, Luis Felipe (2007 y 2008): Fundamentación lógico-formal de la Responsabilidad Social Corporativa. Madrid: Servicio de Publicaciones UCM y Ediciones del Forum Internacional de Comunicación y Relaciones Públicas.

SOLANO SANTOS, Luis Felipe (2008): Patrocinio y mecenazgo: instrumentos de responsabilidad social corporativa. Madrid: Fragua Comunicación.

\section{El autor}

Doctor en Ciencias de la Información por la Universidad Complutense de Madrid y Máster en Gestión Publicitaria (UCM). Profesor Contratado Doctor del Departamento de Comunicación Audiovisual y Publicidad II de la Facultad de Ciencias de la Información de la UCM desde 2001, donde imparte la docencia de las asignaturas de "Patrocinio y Mecenazgo", "Fundamentos de las Relaciones Públicas" y "Fundamentos Psicosociales de la Información". También es Director de Comunicación del Forum Internacional de Comunicación y Relaciones Públicas, así como responsable de numerosos proyectos de investigación tanto a nivel internacional como nacional. Autor de varios libros y artículos publicados en revistas científicas con índice de impacto en el ámbito de la comunicación, entre los que destacan, "Patrocinio y Mecenazgo: instrumentos de responsabilidad social corporativa", "Hacia una nueva concepción de la responsabilidad social" y "Análisis de la imagen: introducción a la iconometría". Mención especial requiere su tesis doctoral "Fundamentación lógico-formal de la Responsabilidad Social Corporativa" (2006), ya que por primera vez se fundamenta la RSC desde una reflexión teorética lógico-formal. 